\title{
Feira industrial e reprodução de classes sociais: da "capital da moda intima" à intimidade do capital
}

\section{André Laino}

Professor e pesquisador na Universidade do Norte Fluminense e na Universidade do Estado do Rio de Janeiro

\section{Resumo}

Esse artigo aborda a Feira de produtos de confecções - Fevest - de Nova Friburgo. Sua montagem visa resguardar à cidade o título de "capital da moda íntima". Nela, o envolvimento político-institucional local, regional e nacional não esconde um processo de seleção e exclusão econômico-financeiro que perpassa a cadeia produtiva e onde, também, se configura o caráter de classe social imprimido à relação entre estética e produção de mercadorias. Palavras chave: indústria de confecções, estética, produção de mercadorias.

\section{Abstract}

This article discusses the Fair clothing products - Fevest - Nova Friburgo. Its assembly aims to safeguard the city the title of "capital of underwear". In it, the political and institutional involvement local, regional and national does not hide a selection process and economic and financial exclusion running through the supply chain and which also configures the social class character printed on the relationship between aesthetics and production of goods.

Key words: clothing products, aesthetics, production of goods.

\section{Resumen}

Este artículo aborda los productos de ropa Feria - Fevest - Nova Friburgo . Su montaje tiene como objetivo salvaguardar la ciudad el título de "capital de la ropa interior". En ella, la participación política y las instituciones locales, regionales y nacionales no oculta un proceso de selección y exclusión económica y financiera que atraviesa la cadena de suministro y que también configura el carácter de clase social, impreso en la relación entre la estética y la producción de bienes.

Palabras clave: productos de ropa, estética, producción de bienes. 
O tema do presente artigo é a Feira de produtos de confecções - Fevest - de Nova Friburgo. Sua montagem visa resguardar à cidade o título de "capital da moda íntima". Focalizaremos particularmente processo de seleção e exclusão econômico-financeiro que perpassa a cadeia produtiva. O objetivo é analisar o caráter de classe social imprimido à relação entre estética e produção de mercadorias no setor têxtil do município.

Durante nosso trabalho de pesquisa de campo, para complementar o levantamento do processo de reprodução da cadeia produtiva de confecções de Nova Friburgo, visitamos a Feira que, anualmente, esse setor organiza na cidade.

Percorrendo os corredores da FEVEST - Feira do Vestuário anual, organizada com participação, principalmente, de grandes e médias empresas de Nova Friburgo - é onde se percebe a existência daqueles valores de "clima de mercado", cujo conteúdo paira prevalecente entre as empresas. Nestes corredores, tudo é voltado para o "fechamento de negócios" com antigos e novos compradores. Esse movimento é encabeçado pelas grandes confecções, por meio de divulgações e propagandas que, meses antes já produzem um burburinho de expectativas na cidade, alcançando as demais médias e pequenas confecções. E também as facções, que são as pequenas oficinas de costura de "fundo de quintal", onde se concentram a maioria das costureiras desta cadeia produtiva. Nos dias que antecedem à feira, são preparadas encenações dentro e fora das confecções, para o "público interno" e "externo".

Grandes compradores, como os magazines, são uma reserva certa de produtos, adquiridos pelo mercado por certo tempo. Eles compram, com bastante antecedência para as estações do ano, quantidades vultosas de mercadorias nas grandes confecções. Por isso, durante a feira estes compradores já têm garantida a prerrogativa de fazerem visitas de inspeção em confecções. Nestas, dias antes da feira, há todo um clima com preparações alimentadas por suposições e expectativas de vendas.

Controladoras - as polis - e outros da direção circulam pelo salão de produção no interior de confecções. Colocam plaquinhas identificando setores, equipes, avisos de locais perigosos, setas de circulação, no chão e nas paredes, na produção e áreas de estoque. Coisas que, normalmente, nunca estão lá. Numa das confecções pesquisadas, cortinas costuradas por uma trabalhadora foram colocadas nas grandes janelas, num dos lados do salão. E, por esse trabalho, ela recebeu como pagamento a metade do valor de uma jornada de trabalho. Algumas costureiras receberam óculos especiais, para trabalharem nas máquinas nestes dias da feira. As encarregadas circulam no salão, pedindo atenção e cuidados com a limpeza nos locais de trabalho. Atendendo exigências de formalização dos magazines, contracheques foram regularizados numa confecção. Segundo uma costureira:

"Ele - o proprietário - regularizou nossos contracheques. Não tem mais nada por fora! Vem tudo no contracheque!"

$\mathrm{Na}$ Fevest de agosto de 2012, como as demais dos anos anteriores, foram apresentados e desfilaram os distintos campos simbólicos que, nas expressões estéticas do "design", expuseram as diversas formas e conteúdos dele enquanto valores agregados às peças de lingeries.

A feira foi montada num espaço de mais de $6000 \mathrm{~m} 2$, abrigando 64 confecções - a maioria absoluta de roupas íntimas - em área cercada de vegetação no Nova Friburgo Country Club. Este clube funciona num dos maiores terrenos urbanos, dentro dele se encontra a residência que pertenceu ao Barão de Nova Friburgo. Toda a área, bastante arborizada, com belos gramados, lagos e caminhos, teria sido cedida ao poder 
público local pelo Barão, ou seus descendentes. É um espaço urbano que, em termos de imaginário, faz parte dos processos seletivos e excludentes que respaldam a reprodução das famílias tradicionais locais, muitas delas ainda residentes nesta área central.

Além das confecções, na FEVEST há stands de empresas de transporte, corretoras de seguros e fábricas de materiais acessórios de confecções, como bojos para soutiens, fitas e fios, cabides e manequins. São montados, também, espaços destinados aos restaurantes da cidade, participantes da feira. $\mathrm{O}$ material de divulgação é bem elaborado, em papel de boa qualidade e com fotos coloridas, acompanhadas dos endereços, fixo e virtual, telefone e um pequeno release da área e produto de cada participante.

Nestes resumos, prevalecem as terminologias que associam à mulher, a imagem de portadora do fetiche contido no "design", que as costureiras das confecções e facções produzem nas peças íntimas. Neles, são frequentes os termos: "maravilhosa", "divina", "incomparável”, "única", "inconfundível”, "inexplicável”, "independente", "sedutora”, "dona de si”, "sensual”, “elegante”, "sofisticada”, "ousada", "irreverente”, "versátil.” Na estética apreendida pelo discurso publicitário este "propõe evocar o universo das conotações privadas... efeito simbólico do anúncio... o encontro... com a aura de correspondências, ressonâncias, analogias... magia e encanto." A mulher é o objeto, portador de todos esses predicados!

No discurso publicitário, todas as formas de trabalho que possam estar contidos na elaboração da estética, são ocultadas por uma "sensibilidade" construída pelo merchandising, que organiza e expõe suas formas de efetivação. A estética adota, então, as expressões técnicas, de ascetismo cultural, dependendo do "nicho" de mercado a que o produto se destina, segundo suas divisões, de classe social e subclasses. Para isso, as campanhas publicitárias adotam estratégias de camuflagem, cheias de pretensões literárias aplicadas sobre a moda íntima. Tais pretensões fazem parte dos invólucros criados pela reprodução, e aplicados às mais diferentes mercadorias. Bourdieu encontrou o uso de termos semelhantes, com as mesmas presunções literárias, acompanhando os discursos publicitários voltados para a divulgação da casa: "mistério, charme, natureza, proporções, tradição, região, espaços, volumes, pátio, mezanino... história, alma." (BOURDIEU, 2007).

Nestas estratégias, são largamente aplicados à estética um vocabulário cujos termos remetem ao enaltecimento de "uma arte única", remetendo a uma dissociação das "medíocres" sensações comuns que sejam rapidamente acessíveis e reprodutíveis. Todo o vocabulário deixa implícito que o leitor (a) de tais mensagens deve ter algum preparo nas sensações, para que as percepções possam captar as sutilezas do objeto. Estas se compõem de sensações e percepções que remetem a determinadas condições de privilégio de classe social que, por meio do acesso à mercadoria, geram no consumidor a impressão, ilusoriamente materializada no produto, de ter tido acesso aos valores materiais e imateriais associados a elas. São estratégias que visam camuflar, diluir e afastar-se da produção de massa à qual, na realidade, todas as mercadorias pertencem. Pois, a massificação as torna, essencialmente, contrárias ao privilégio da personalização e individualização, acessível a certos atores de determinadas classes sociais na qual, por meio da diferenciação anexada à mercadoria, o comprador pretende estar envolvido.

Essas terminologias são, portanto, partes fundamentais da elaboração do imaginário construído pela reprodução da cadeia produtiva do setor de confecção. Elas associam razão e justificação, no recorte e montagem dos elementos estéticos aplicados ao 


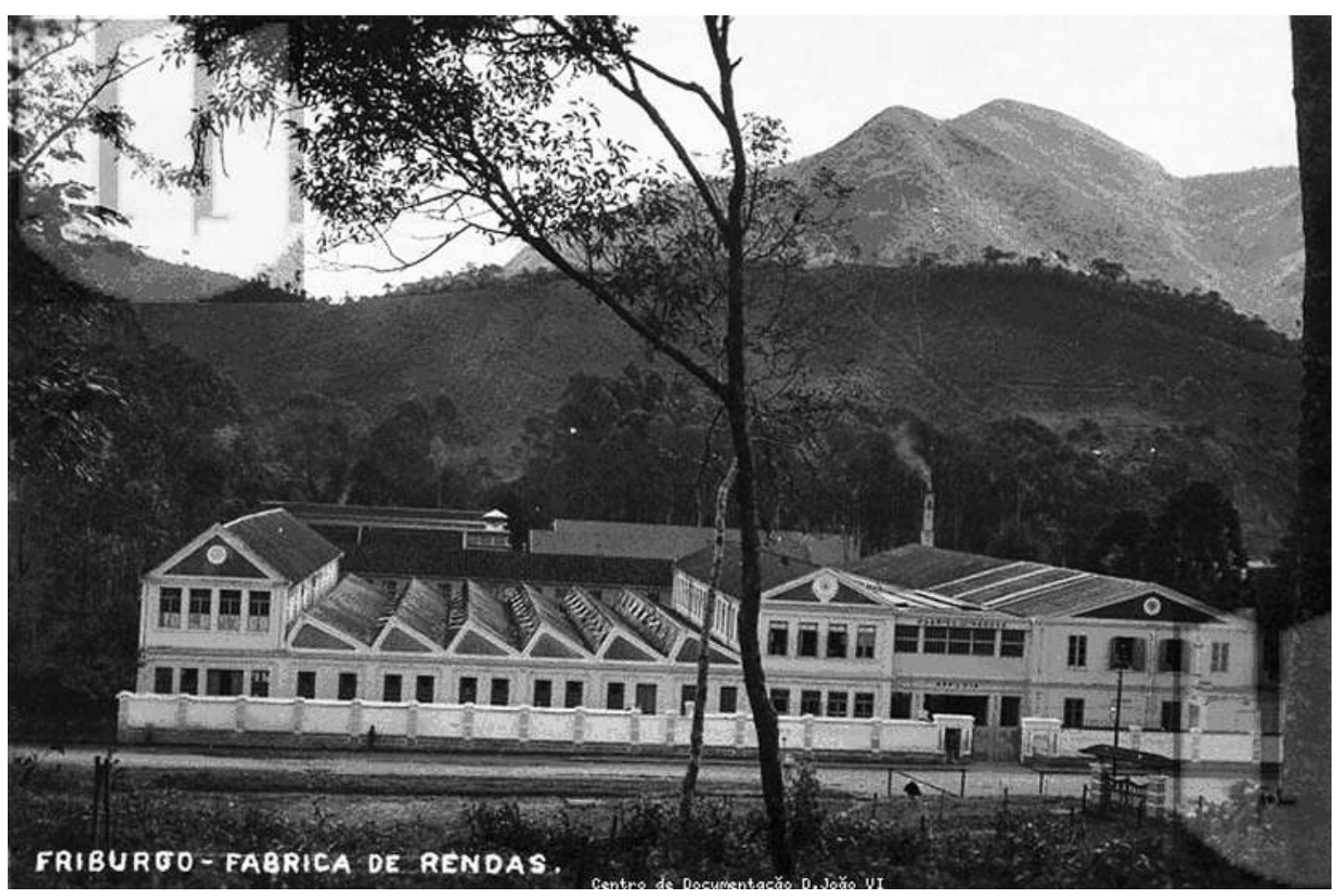

Fábrica Rendas Arp em Nova Friburgo no início do século XX.

Fonte: http://historiadefriburgo.blogspot.com.br/2011_06_01_archive.html.

design das peças na produção da mercadoria, anexando-os aos atributos conferidos à feminilidade. Estes, guardando amparo e receptividade no senso comum, são respaldados, reforçados e divulgados pelos instrumentos de propaganda e comunicação de massa. Isso fica evidente em todo o espaço físico da feira: uma extensão, e continuidade, dos temas de propaganda dos outdoors de roupas íntimas, espalhados em diversos pontos da cidade.

$\mathrm{Na}$ entrada da Feira, uma sala multimídia projeta curto documentário. $\mathrm{Na}$ filmagem, feita numa confecção, operárias aparecem em tomadas rápidas e laterais do rosto curvado sobre as máquinas de costura, e algumas mãos manuseando peças e manejando máquinas. Em seguida, num longo corredor com diversos manequins vestidos com diferentes estilos de peças íntimas, são representadas as confecções presentes na feira. Antes da área da feira propriamente dita, há uma segunda filmagem, onde operárias aparecem em tomadas de corpo inteiro, alegres e sambando num salão de trabalho, em meio às máquinas. Segue-se um grande espaço ocupado por estandes de representantes do Estado do Rio, e de Instituições federais de bancos e entidades ligadas a empreendedorismo. Neste espaço confirma-se a presença dos interesses socioeconômicos e financeiros, presentes no Polo de Moda Íntima de Nova Friburgo, que vão muito além do âmbito municipal. Eles fazem parte do conjunto de arranjos produtivos locais - APL - que, por meio das micro e pequenas empresas - MPEs visam um desenvolvimento integrado em concordância estratégias de desenvolvimento nacionais e globais. Tais estratégias são implementadas pelas atuações do Serviço Nacional de Aprendizagem - Senai - e o Centro de Tecnologia da Indústria Química e Têxtil - Cetiqt. E, por seu turno, as linhas mestras do Senai e Cetiqt provêm do GT/APL - Grupo de Trabalho Permanente para Arranjo Produtivo Local - do MDIC - Ministério de Desenvolvimento, Indústria e Comércio Exterior.

Mas, nesse trajeto, o visitante tem atenuado o verdadeiro peso desses interesses ao ser gradualmente introduzido no fetiche do "encanto e da beleza" das mercadorias, 
misturados a imagens visando induzi-lo a considerar o artesanato como o grande produtor da sensualidade. O percurso é, ainda, entremeado de estandes de campanhas, visando amortecer ou desviar do caráter iminentemente mercantil da feira. Assim, num deles o soutien é, indireta e tenuemente associado com a campanha para controle do câncer de mama.

Neste sentido, é pertinente uma analogia com as concepções de "capital fictício" e "novas dinâmicas internas da abstração", apresentadas por Fredric Jameson. A primeira expõe a contribuição de David Harvey ao entendimento do valor da terra em Marx. $\mathrm{Na}$ segunda, Jameson faz referência ao ensaio de Simmel, que trata da multiplicidade de formas de abstração da teoria das formas estéticas modernas, cuja matriz e ponto de irradiação é o dinheiro. Vejamos algumas delas.

Estendendo a aplicação daquelas concepções à estética, uma vez apropriada pelo mercado ela adotaria os contornos de um repositório de "capitais fictícios". Tal mutação faz da cultura, que se move em seu interior, um campo pessoal e socialmente etéreo, indefinido e desconectado das condições sociais e econômicas concretas. Por isso, ele é apresentado como potencialmente rico e diversificado o suficiente para abarcar, e se apropriar, dos novos e inusitados elementos aos quais a estética seja apresentada. Sem com isso, óbvia e ficcionalmente, ameaçar a reprodução econômica e, principalmente, social onde tal processo esteja ocorrendo. Essa força e riqueza lhe permitem estender-se, incorporando a ela a sugestão de Simmel da anexação de "novas dinâmicas internas da abstração". Estas trariam novos meios e instrumentos para a reprodução dos elementos, materiais e imateriais, que compõem o imaginário atrelado àquela reprodução. Para melhor fundamentação e entendimento da analogia que propomos, vejamos o trecho do texto de Jameson:

"Harvey sugere que para Marx o valor da terra é algo como uma fição estruturalmente necessária... ele a chama... 'capital ficticio' - 'uma corrente de capital desprovida de suporte de qualquer transação comercial' -... orientado para a espera de um valor futuro... intimamente relacionado com o sistema de crédito, o mercado de açóes e capital financeiro... Numa análise da abstração da vida moderna... Simmel, a abstração toma uma multiplicidade espantosa de formas... o dinheiro é a causa de todos esses novos fenômenos... o a fastamento das antigas formas de percep̧̧ão... a ascensão da abstração no interior do próprio dinheiro... capital financeiro... também nos deparamos com novas dinâmicas internas da abstração."(JAMESON, 2001).

Mas, para participar dessa celebração do imaginário voltado para a "espera de um valor futuro" que é a FEVEST, onde o fetiche é parte constante da mercadoria adornando-a de "novas dinâmicas internas da abstração", um confeccionista tem de desembolsar valores financeiros pelos estandes, dependendo do tamanho e posição pretendida - e possível! - no interior da feira.

Esses valores variam de acordo com a posição ocupada no espaço do interior da feira. Os estandes situados nas esquinas, e pontos de passagem, são os mais caros. Os localizados nos corredores são mais baratos. Em 2012, já estavam sendo comercializados os estandes para a feira de 2013. Os valores eram, para serem adquiridos durante a feira, 1 - stand de $12 \mathrm{~m} 2, \mathrm{R} \$ 3.900,00$ a vista, ou $\mathrm{R} \$ 4.300,00$ parcelados em 10 vezes; 2 - stand de $24 \mathrm{~m} 2, \mathrm{R} \$ 7.800,00$ a vista, ou $\mathrm{R} \$ 8.600,00$ em 10 vezes. Se a confecção comercializasse após a feira, esses valores subiriam, respectivamente, para: $R \$ 4.300,00 R \$ 4.700,00$, para pagamentos a vista, e, $R \$ 8.600,00$ e $R \$ 9.400,00$ 
para pagamentos parcelados. São valores altos e distantes das condições de pequenos confeccionistas. E completamente fora da realidade dos faccionistas. Vejamos, sucintamente, como essas distintas condições se concretizam nas relações de produção e trabalho concretas.

A condição de faccionista é formada pelas pequenas oficinas de fundo de quintal, com duas ou mais costureiras trabalhando informalmente. Além disso, o faccionista contrata ocasionalmente - dependendo de suas avaliações das oscilações do mercado - algumas costureiras que trabalhem em casa, nas proximidades de sua oficina. Nesta oficina, e nas que trabalham em casa, costureiras montam partes de peças, ou peças inteiras que, em geral, o faccionista vai pegar nas confecções, médias ou grandes. $\mathrm{Na}$ reprodução da cadeia produtiva, o projeto sempre presente, e fomentado no imaginário do faccionista, é montar uma confecção. No entanto, a frequência, profundidade e intensidade das oscilações do mercado, trazem consigo as instabilidades que perpassam toda a cadeia produtiva. E estas recaem, principalmente, sobre tais facções.

Deve-se ressaltar que, em geral, a condição de instabilidade atinge, também, o pequeno confeccionista. Este, para enfrentá-la, faz reavaliações cotidianas dos valores, materiais e imateriais, envolvidos no processo de produção. A instabilidade é uma marca deste processo, sendo uma barreira cujas configurações de mutações imprevisíveis, submetem e exigem dos atores adaptações constantes, produzindo desgastes físicos e mentais. Com pequenas variações entre eles, tais desgastes se distribuem entre todos os atores envolvidos no processo de produção, contribuindo para esgarçar as relações de trabalho. As tensões e conflitos, latentes ou manifestos, que emergem daí, demarcam a condição de participação restrita a que poucos, de fato, conseguem, e que é aquela de cruzar, chegar e se manter na situação de confeccionista. Por isso, aqueles valores financeiros exigidos para ocupação de espaços na feira, se revelam excludentes para a grande maioria dos partícipes da cadeia produtiva. Como nos disse uma costureira, elas não precisam ir. Pois, já estamos lá "com nosso trabalho."

Participam da feira, também, artistas com divulgação na mídia televisiva. Geralmente como convidados ou, mais raros, com cachês pagos pelos confeccionistas. Há palestrantes com temas sobre moda, estética e humanização da criação e do empreendedorismo. A montagem, propaganda e divulgação da feira são feitas pelo Sindicato da Indústria do Vestuário - Sindvest - cuja maioria dos membros é composta pelos médios e grandes confeccionistas.

Em outros estandes, no interior da feira, também estão dispostas algumas televisões com gravações de imagens de produtos de empresas. Um deles se destaca pela filmagem, enfatizando algumas fases da produção de um soutien. Aparecem mãos cuidadas e com unhas bem feitas de uma costureira. A ênfase da filmagem recai sobre o manuseio atento e calmo dos tecidos, e demais partes para a montagem da peça. Mãos aparecem em movimentos cuidadosos, manuseando algumas máquinas: a uma agulha, a duas agulhas, a Overlock, a Interlock, etc. Os movimentos de colocação das peças são lentos, visando mostrar extrema atenção da costureira. O objetivo da imagem é transmitir que a execução do trabalho está sempre direcionada para a perfeição das etapas. Mais próximos, portanto, de um trabalho artesanal do que propriamente fabril, ou de facção. Essa filmagem apresenta ao expectador um tempo de produção que, como vimos no decorrer posterior da pesquisa nas confecções e facções, estão distantes e distintas do ritmo frenético das condições concretas de trabalho. Estas são 
longínquas do imaginário artesanal que tal filmagem procura remeter, distorcendo e reduzindo o entendimento das reais condições de trabalho das costureiras.

No estande em frente, ao contrário dessa "estética artesanal" uma tv apresenta um filme com outro roteiro. Sobre um fundo musical agitado, e em tomadas de cenas rápidas, belas mulheres em poses provocantes apresentam peças íntimas da linha sensual. O fetiche que embala a mercadoria é, neste caso, aquele da "estética da sensualidade".

Os frequentadores da FEVEST não são somente compradores e expositores. No primeiro dia, sempre havia alguns políticos, cumprimentando empresários de setores ligados ao setor têxtil, ou os donos de confecções. Dentro dos estandes e nos corredores, ocorriam as vendas e interconexões de contatos das redes de negócios entre as empresas. Mas, estes movimentos não são exclusivamente comerciais.

A feira contém um mix de aspectos empresariais e familiares. Além dos proprietários das confecções e alguns funcionários, - em geral dos escritórios ou da seção de modelagem - diversos familiares estão nos estandes. Neste primeiro dia havia filhos, irmãos, netos e avôs se misturando a compradores. Os mais idosos são, em geral, os pais de alguns donos de confecções, bastante reconhecidos quando passam pelos demais estandes. Eles desfilam pelos corredores a importância da confecção que representam, transmitindo simbolicamente o aspecto marcante e distintivo da origem, enquanto reforço da marca de honestidade e confiabilidade da confecção. Tais atores propagam as marcas da distinção por meio das quais se anexam ao processo de reprodução.

Neste sentido, esses gerentes transitam pela feira o símbolo dessa origem, remetendo, com a presença destes atores “tradicionais”, à importância do setor confecção na história e reprodução da sociabilidade contemporânea de Nova Friburgo. Pelos corredores da feira, eles ostentam o que seria o prêmio do ascetismo e do equilíbrio, obliterando nestas caminhadas os verdadeiros núcleos da família burguesa: as heranças e suas ampliações por meio da apropriação da mais-valia. E, chamando a atenção para tais famílias, por meio desses artifícios da reprodução de tais valores - aceitos e almejados pela maioria dos participantes da feira - desviam a compreensão do essencial: as origens de suas riquezas e a extorsão da mais-valia. (BAUDELOT, 1971).

Em meio aos diferentes estilos estéticos, esse ambiente de cordialidade e informalidade aparente nos corredores da feira, dissimula a luta ferrenha pelo mercado entre as confecções. Neste clima, cercado das amostras dos mais diferentes tipos, cores e estilos estéticos de peças íntimas, escamoteiam-se as profundas diferenças nas formas de expropriação da força de trabalho e das taxas de acumulação dos diferentes capitais. Tais diferenças estão contidas nas distintas agregações de valores, segundo os recursos de materiais estéticos utilizados nas peças que, enquanto mercadorias, contêm os valores materiais e imateriais, como marcas distintivas das condições sociais a que se destinam. Tais marcas regulam as aproximações entre confeccionistas e compradores, estabelecendo a razão dos diálogos nos estandes por meio dos valores que perpassam suas negociações, onde a sensibilidade estética é entremeada pela presença permanente das diferenças socioeconômicas instaladas no mercado. Num dos estandes, presenciamos essa conversa entre, a proprietária de uma grande confecção com dois compradores. Ela diz:

- "O mercado popular é de produtos mais simples."

O comprador complementa:

- "Mostra tudo!"

A proprietária responde: 
- "Os grandes magazines querem produtos mais elaborados."

O comprador, buscando mostrar entendimento, acrescenta:

- "Ou mostra tudo. Ou esconde tudo."

A lingerie que "mostra" - popular - é mais barata, porque "mais simples". Essa mercadoria contém menos valor agregado. Tanto em termos do capital constante, de máquinas e matérias-primas, quanto de capital variável. Pois sendo mais simples o design da peça, as intervenções da costureira são menos frequentes. Enquanto para "esconder", a peça é mais cara. Pois, contém "mais elaboração". Que significa mais riqueza, criada pela força de trabalho e demais valores de máquinas e matérias-primas, transferidos e agregados pela mesma força de trabalho. Então, "mostrar" no sentido da proximidade, não é sofisticado. Enquanto o mostrar, enquanto "esconder" no sentido do distanciamento contido, é sofisticado, distintivo, caro ou, "mais elaborado".

Neste sentido, a mesma distinção de "público destinado", com todo embasamento distintivo conferido pelo conteúdo socioestético, é aplicada também nas mercadorias da construção civil, conforme aponta Bourdieu: "O ajustamento da oferta e da procura não é o resultado de uma milagrosa agregação de inúmeros milagres obra de entes racionais capazes de concretizar as escolhas mais conformes aos seus interesses. Contrariamente às aparências, nada há de natural nem evidente no fato dos compradores com menos posses recorrerem às sociedades que oferecem produtos mais mediocres, sobretudo esteticamente, enquanto os outros se dirigem 'espontaneamente' para as empresas que ocupam no espaço dos produtores posições homólogas à sua posição no espaço social, ou seja, para os produtores e produtos mais adequados a satisfazer o seu gosto de conforto, de tradição, de originalidade, em resumo, o seu sentido de distinção." (BOURDIEU, 2007) (Grifos nossos).

$\mathrm{Na}$ mercadoria destinada ao "mercado popular", os valores menores nela embutidos permitem ao consumidor mais fácil e rápida chegada ao conteúdo. Pois, não está associada a instrumentos sofisticados de decodificação para o acesso. Naquelas mercadorias destinadas aos mercados "mais elaborados", ou sofisticados, os valores maiores nela embutidos já preveem um consumidor dotado de uma capacidade de decodificação e acesso a tais conteúdos, baseada em meios de percepção e leituras sofisticados. Os valores maiores contidos em tais mercadorias são direcionados ao consumidor que possua condições, materiais e imateriais, de acesso a tais meios e instrumentos especiais. Essa é a leitura como a reprodução, por meio destas distinções entre mercadorias, associa a produção delas - desde seus projetos de design! - a dois tipos socialmente distintos de olhares e vivências do mundo. E, também, onde as campanhas de divulgação e propaganda conferem às diferenças de sensibilidades o invólucro do mercado sacramentando, enquanto expressão hegemonicamente significativa, aquelas distintas condições de classe pela legitimação daqueles olhares e vivências ${ }^{1}$.

Para demonstrar, e esclarecer, como atuam as imposições de distinções presentes nas relações entre os atores, e que se expressam nos usos sociais imprimidos à percepção, Bourdieu indica, como exemplo histórico, a diferença que emerge com a anexação da "visão escolástica" aos "sentidos de proximidade" no desenvolvimento da criança. Então, ele escreve:

1 Ocorre o mesmo na reprodução da "distinção" entre o mercado da música popular e aquele da erudita. Nele, o custo da formação da "sensibilidade" está associado ao conjunto de valores imateriais, vinculados à condição de acesso aos meios materiais de formação de sensibilidade "de classe". 


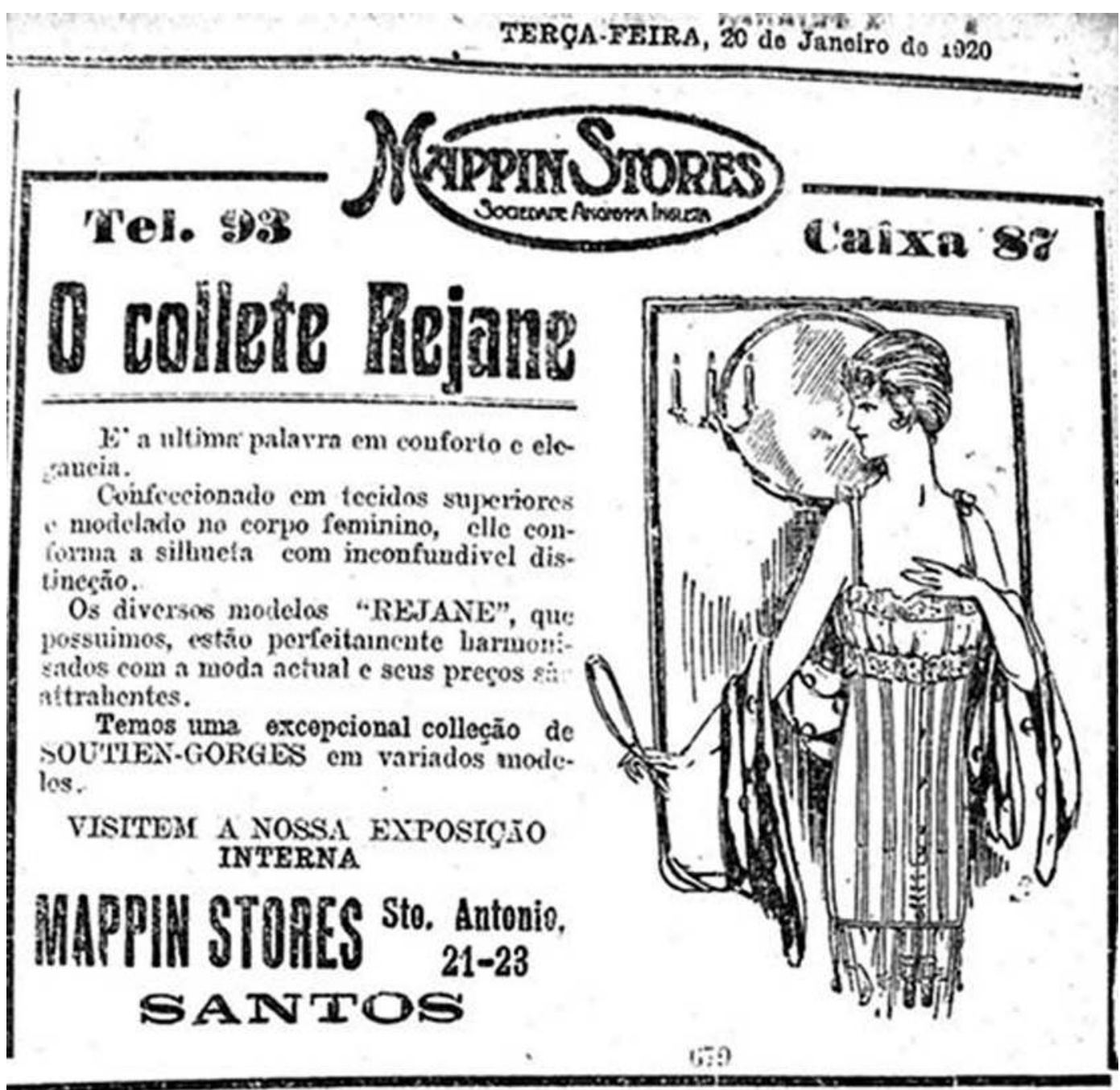

Anúncio de roupa feminina de 1920. Fonte: http://mrclaund.blogspot.com.br/.

"Para se compreender inteiramente o processo de construção social desse olhar distante e altivo, dessa verdadeira invenção histórica que é o 'olhar escolástico'... Com base numa transposição... Ernest Shachtel... no desenvolvimento da criança a atribuir.. a preeminência aos 'sentidos de distância', a vista e o ouvido... visão objetiva e ativa do mundo, em detrimento dos 'sentidos' de 'proximidade', o tato e o paladar, voltados para os prazeres e desprazeres imediatos,poder-se-ia alcançar a hipótese de que a conquista da visão escolástica, objetivada na perspectiva, se faz acompanhar de um afastamento em relação aos prazeres ligados aos 'sentidos de proximidade'. Tal afastamento se retraduz... por um recalque progressivo... da primeira infância... tidos como vergonhosos. Dando lastro a essa hipótese... observações históricas de Lucien Febvre, em seu livro sobre Rabelais, ao constatara predominância, na poesia do século XVI, do olfato, do paladar e do tato, e a relativa ausência de visuais." (BOURDIEU, 2007b, 33-34) (Grifos nossos).

O que confirma, também, que a produção para o mercado nada tem de "mão invisível”! Traz na sua matriz, a reprodução das classes sociais às quais ela está destinada. Mesma conclusão que chegou Bourdieu, ao fim de um dos capítulos de seu trabalho sobre a construção civil: "Somos levados a substituir o mito da 'mão invisivel', elemento fulcral da mitologia liberal, pela lógica da orquestração espontânea das práticas, baseada em 
toda uma rede de homologias. Esta espécie de orquestração sem chefe de orquestra está na base de estratégias que poderemos considerar sem sujeitos, porque são mais inconscientes do que propriamente desejadas... entre os habitus dos compradores e dos vendedores." (Grifos nossos). (BOURDIEU, 2007, p. 108) (Grifos nossos).

Ao mesmo tempo, o diálogo anteriormente descrito revela que, embora destinada a reproduzir, por meio da produção, a manutenção e continuidade das diferenças no mercado entre o que "mostra tudo" e o que "esconde tudo", pouco importa à reprodução da cadeia produtiva da confecção se a costureira está produzindo para um, ou outro. Importante é que ela produza para os dois, ora um ora outro, adaptando sua força de trabalho às diferenças de abstração necessárias ao trabalho da produção de uma ou outra mercadoria. Seja às poucas exigências da peça que "mostra tudo", ou às exigências sofisticadas daquela que "esconde tudo". Assim, nas palavras da "poli" - controladora de avental vermelho da confecção maior, onde fizemos pesquisa de campo - enquanto costurava uma peça, e explicava a costureira a seu lado como devia trabalhar:

"Ninguém está questionando aqui se você é boa costureira, ou não. Aquilo que dá para fazer, faz. Aquilo que não dá, deixa para $2^{\mathrm{a}}$ feira."

No plano geral, que se expressa nas formas imediatas da reprodução econômica, a expressão adotada por essa distinção social, que também vai imprimida na mercadoria por meio de complementos estéticos, não afeta a acumulação. É apenas mais um elemento do capital constante, matéria-prima e máquinas, a ser anexado à mercadoria. E o capitalista, por seu turno, vive acumulando, sem qualquer interesse em descortinar a composição da reprodução contida nas relações entre produção econômica e distinção social. Assim, quando comentamos com o proprietário dessa confecção, que já havíamos feito trabalho de pesquisa numa metalúrgica de produção de tubos, ele comentou:

"Produzir soutien ou tubo, é tudo igual".

Contudo, aquela relação entre produção econômica e distinção social está presente na visão de mundo deste proprietário de confecção, na sua relação e atuação nele enquanto acumulador. Apesar de estar ausente no seu entendimento dessa mesma visão do mundo, por uma exigência ancorada no ponto dessa atuação dele na reprodução, que era o porte e local dele, enquanto capitalista, na cadeia produtiva do setor de confecção. Essa ausência só desaparece em certos momentos políticos, quando o entendimento nesse mundo obriga a tirar proveito das aproximações com sua relação e atuação nele. Em relação a essa pesquisa, por exemplo, o proprietário buscou direcionar seu entendimento no sentido de aproveitar, ao máximo, todas as oportunidades que se descortinavam com sua atuação na relação entre o econômico e o social na reprodução. E a pesquisa que apresentamos a ele, não deixou de fazer parte dessa estratégia. Afinal, "tudo é igual”.

\section{Referências bibliográficas:}

BAUDELOT, Christian e ESTABLET, Roger. L'école capitaliste em France. Paris: Maspero,1971.

BOURDIEU, Pierre. Meditações pascalianas. Rio de Janeiro: Bertrand Brasil,2007 - As estruturas sociais da economia. Porto: Campo das Letras, 2007. 
JAMESON, Fredric. A cultura do dinheiro. Ensaios sobre a globalização. Petrópolis: Editora Vozes, 2001.

Artigo recebido em novembro de 2015 e aprovado para publicação em janeiro de 2016. 